\title{
A Cognitive Metaphoric Study of English Animal Idioms
}

\author{
Zhimin Xiang \\ Sichuan Preschool Educators College \\ Mianyang, Sichuan, China 621709
}

\begin{abstract}
Conceptual metaphor theory is a significant theoretical output in cognitive linguistics. Animal idioms in English are large in number and revealing in cognitive mechanism. The present paper is aimed at a cognitive metaphoric study of English animal idioms from the perspective of conceptual metaphor theory.
\end{abstract}

Keywords-metaphor; conceptual metaphor theory; English animal idioms

\section{INTRODUCTION}

Language is a hierarchical system of words and symbols used for human communication. Being a product of culture, it is a reflecting mirror of a culture and the thinking patterns of a speech community. It is an organic whole with multiple layers, usually starting from sounds and culminating in texts or discourses. And naturally it won't be an integral entity without some of its most fundamental components, for example idioms. Idioms are meaningful chunks of a language and its corresponding culture. They are crystallizations of a specific culture, with relatively set structure and literally undecipherable meaning. To a large extent, idioms are easy to come by and difficult to interpret. The efficient use of idioms in a language is often a living proof to a person's command of the language. English animal idioms are a distinctive part in English idiom world. They are rich in ethical cultural implications and they account for an impressive portion in English idioms. Take a well-known animal idiom "shut up like a clam" for example. It is so vivid that it evokes an image of clam in our mental world to illustrate the meaning "somebody choose to withhold some information and keep silent". Given the research status-quo concerning English idioms, it is heartening that idioms as a whole has been a hot research topic of various schools of linguistics and attracted a great deal of attention of many academics. Yet with the literature at hand we have to say that animal idioms as a subgroup of English idioms haven't got enough research limelight it deserves. Previous studies have mainly focused on the rhetoric functions and translation methods of English idioms. Studies with specific idiom data from a comprehensive cognitive approach are more often than not few and far between. To fill the gap, the main purpose of the thesis is to interpret the cognitive mechanism of English animal idioms from the perspective of conceptual metaphor theory. The first section gives an overview of the theory and offers a glimpse into the inevitable difficulties English idioms as a whole has afforded English language learners. The most challenging part in learning English idioms is cultural context and corresponding cultural concept. Something that seems so common sense and therefore usually gets taken for granted in one culture has to be explained in great details in another culture. The second section, on the basis of conceptual metaphor theory, sets out to a new interpretation of English animal idioms: animal idioms under conceptual metaphoric perspective. Section two is the main body of the thesis. In the third section, we point out another important discovery of our animal idiom study: besides being first and foremost human, a specific species of animal can also be another quite different species of animal. Some examples are provided for the interpretation of animal idioms under the new theoretical perspective and the illustration of the cultural differences. Finally, we come to the conclusion part of the thesis. In the conclusion part, we tend to underscore the significance of the present study. In a nutshell, this paper contributes to a specific inquiry into the niche subgroup of English idioms rather than a general study of English idioms. We hope that this study can serve as a meaningful attempt in the field of English idiom study from a cognitive perspective and shed light on our human cognitive mechanism.

\section{THE THEORETICAL BASIS OF THE PRESENT STUDY}

Conceptual metaphor theory, one of the centerpieces in cognitive linguistics, is put forward by Lakoff and Johnson in their book Metaphors we live by. Up till now when we look back, it is still a milestone in both metaphor studies and cognitive linguistics. Before conceptual metaphor theory, metaphor is just a rhetoric device like simile, a linguistic spice to make language interesting. After the conceptualization of this groundbreaking theory, metaphor has bid farewell to the somewhat old, beaten track of rhetorical approach and blazed a new trail of cognitive approach. According to Lakoff and Johnson (1980), metaphor is essentially a cognitive device for us to organize our thinking and categorize our experiences. Under Lakoff \& Johnson's theorizing, to say one thing in terms of another that is of a different category constitutes metaphor. In technical terms, metaphor is cross-space mappings between different cognitive domains. To make a cross-domain mapping possible, one needs a source domain, a target domain and some conceptual similarities between two domains to trigger the mapping process. Generally speaking, 
the cross-domain mapping process is systemic, partial and largely asymmetric. The mapping relations fall into two different categories: ontological correspondences and inference pattern correspondences. The former refers to the material analogies between two cognitive domains and the latter refers to the more abstract inheritance, succession relations between two thinking patterns. Etymologically, the word "metaphor" is from Greek. The prefix "meta" means "across" and the root "phor" means "to carry". Put together, we can understand metaphor as "to carry properties, thinking patterns of cognitive domain A across to cognitive domain B. And we need to pay attention to the convention that in Lakoff and Johnson's theoretical framework, a conceptual metaphor is usually designated all by capital letters. For example, we have "INFLATION IS AN ENEMY". As for the classification of conceptual metaphors it can usually be divided into root metaphors and derivative metaphors. Take the conceptual metaphor "ARGUMENT IS WAR" for example. It is a typical root metaphor with a huge derivative power. For this root metaphor, we have the derivative metaphors like "He attacked every weak point in my argument", "If you use that strategy, he will wipe you out"; "I've never won an argument with him", etc. And another classification criterion divides conceptual metaphor into three sub-categories: structural metaphor, orientation metaphor and entity metaphor. For our present study, we have come to realize the fundamental metaphorical concept underlying all English animal idioms is "ANIMALS ARE HUMANS (or HUMANS ARE ANIMALS)". It is an entity metaphor per se. And this metaphoric concept holds water since humans essentially evolve from animals or primates specifically. Humans have inherited a great number of physical properties from primates; on the other hand animals as contributing source domains have a lot to offer to human cognitive domain. This point can never be born out more clearly than English animal idioms. Actually nearly all animal idioms are designated to describe humans and their activities or emotions. In the following section, we are going to have a more detailed discussion of this point. Before we delve into the next section, another point worth pointing out is that while in English and Chinese we have a common core concerning animals, each culture has its own distinctive animal idioms. For example in Chinese we have "si bu xiang (neither fish nor fowl)" and in English we have "codfish aristocracy" to mean the new money. And even for some common animals, the associative meanings of animal have varied from culture to culture. For instance in English the dog idioms are more neutral. We have both "lucky dog" and "lead a dog's life" in its dog idiom bank to denote different aspects of life. However in Chinese dog idioms are more often than not derogatory. We have "gou tui zi" to describe an accomplice and "zhu gou bu ru" to belittle a person who is even lower than pigs or dogs. And these disparities in cultural conventions and associative meanings are the reason why there are so many misunderstandings concerning the use and interpretation of animal idioms across different cultural contexts. To bridge the gap between cultures, we must enhance our cultural awareness when encoding and decoding animal idioms. The awareness that different cultures have different conventions and mental associations concerning animals is a first step to start with. To be more specific, one need to consciously do a cultural paradigm shift when he deals with animal idioms from a different culture, he needs to constantly remind himself that the animal idiom in front of his eyes is a living organism embedded in a quite distinctive cultural context and therefore all the previous mental assumptions he has held in his mind about the animal in question can be invalidated, to achieve a successful interpretation of the animal idiom, he must willingly leap out of his own culture and immerse himself into a new cultural context and its corresponding processing codes concerning animal idioms. And when in doubt it is better to check with native speakers than assume on his own.

\section{ANIMAL IDIOMS UNDER CONCEPTUAL METAPHORIC PERSPECTIVE}

As we have mentioned above, conceptual metaphor theory is a trailblazing cognitive theory concerning metaphor studies. This theory has raised metaphor studies from the deep well of rhetoric perspective to the open horizon of cognitive perspective. Equipped with conceptual metaphor theory we are empowered to look beyond its rhetoric functions and get to see the tip of the colossal cognitive iceberg behind animal idioms per se. Under the metaphoric concept "ANIMAL IS HUMAN (or HUMAN IS ANIMAL)", animals take on the human dimensions; they have human's emotions and can even perform human actions. And for the convenience of our study, we tend to categorize our data into three subgroups: "the like pattern", "the as... as pattern", and "the whole sentence as a metaphoric frame pattern".

\section{A. Animal Idioms: "The Like Pattern"}

For this subgroup we have easily found the following examples:

Fight like cats and dogs (fight tooth and nail)

Die like a dog (die in a miserable way)

Lie like a dog (an ill-intentioned lie)

Like a dog with two tails (very happy, rapturous)

Treat somebody like a dog (abuse somebody, not take somebody seriously)

Work like a dog (work very hard and sedulously)

Like a carrot to a donkey (very big enticement)

Like a duck takes to water (something very easy, like a piece of cake)

Like a dying duck in a thunderstorm (in a blue funk, crest-fallen)

Like water off/from a duck's back (to no avail)

Waddle like a duck (to walk unsteadily)

$\cdots$

Just as old English saying goes, one may know by a handful the whole sack. The above examples are only a tiny 
small fraction of "the like pattern" animal idioms in English yet they are very revealing about the metaphoric concept of "ANIMAL IS HUMAN (or HUMAN IS ANIMAL)". Take the first and the third animal idiom "fight like cats and dogs" and "lie like a dog" for example. Both the verb "fight" and "lie" are typical action verbs of human beings, however, with the powerful mechanism of conceptual metaphor theory, animal as a cognitive domain has inherited a set of human features from the source domain "humans". Therefore animals can fight or lie just like a typical man or woman. Animals can be human beings under cognitive metaphoric perspective, and the mapping process or direction can also be the other way around. In other words, the metaphoric concept "HUMAN IS ANIMAL" also holds true as they are instantiated in the examples such as "Treat somebody like a dog", "Work like a dog", "Waddle like a duck"; and "Like water off/from a duck's back", etc. All these "like pattern animal idiom" examples serve as a good showcase for the impressive generating and interpreting power of conceptual metaphor theory.

\section{B. Animal Idioms: "The as ... as Pattern"}

Compared with the first "like pattern" animal idioms group, this subgroup of animal idioms is less eye-catching since they are without the tip-off word "like". Yet they are just as productive as the first subgroup in its generating power. Now let's take a look at the following set of the "as...as" pattern of animal idioms:

As sick as a dog (very ill)

As loose as a goose (completely relaxed)

As silly/stupid as a goose (be silly)

As mad as a wet hen (very mad)

As scare as hen's teeth (very scarce or rare)

As independent as a hog on ice (seemingly very independent)

As sick as a horse (seriously ill)

As strong as a horse (very strong and fit)

As weak as a kitten (very weak)

As meek as a lamb (very tender or credulous)

Examples abound in this subgroup yet due to limited space, we can't list all of them out. For this subgroup, we have noticed that the metaphoric concept behind all these animal idioms is "HUMAN IS ANIMAL". Actually it is easy to understand that we are liable to make analogies between ourselves and our animal friends since we are usually living side by side. This common sphere of living activities inevitably enables us to compare our various living conditions to those of animals. And more often than not the closer an animal is to us; the easier it will manifest itself in an animal idiom. This point can be well illustrated by the "goose", "hen", "horse" metaphors in the above examples. And another point which calls for our attention is that as an animal has so many features as an entity, it can enter an animal idiom world in different ways. For example, for a horse, it is usually very strong and ready for burden-bearing, yet when it is taken ill, it can also be quite indisposed for a couple of days. Thus we have the two corresponding animal idioms "as strong as a horse" and "as weak as a horse". The same inferential logic applies to the two goose idioms "as silly as a goose" and "as stupid as a goose". In a nutshell, these animal idioms afford us a unique way of viewing the world and expressing our feelings.

\section{Animal Idioms: "The Whole Sentence as a Metaphoric Frame Pattern"}

This subgroup is also very common in the entire animal idiom kingdom. The most distinguishing property of this subgroup is that although it is without the metaphor operative words like "as...as" or "like", it is equally convincing in expounding a view. Here we have the following examples:

Guests and fish stink after three days. (As a quest you should not overstay your welcome) do)

Have (got) other fish to fry (have other plans or things to

He has fished well and caught a frog. (Much exertion without impressive returns)

The tortoise wins the race while the hare is sleeping. (Pride goes before a fall.)

Have/get ants in one's pants. (Edgy, be not at ease)

Make/follow/take a beeline/ bee-line to/for (take a straight line or make a short cut)

Have a bee in one's bonnet (obsessive with a thought or seem a little crazy)

Put/drop a bug in somebody's ear (give somebody the heads-up)

Have/get/feel the butterflies in somebody's stomach/tummy (a little fidgety or nauseous)

An old goat is never the more revered for his beard. (Wisdom and age don't necessarily go hand in hand)

Help a lame dog over a stile (give a helping hand to somebody in distress)

Kill the goose that laid/lays the golden $\operatorname{egg}(\mathrm{s})$ (overexploit an asset)

In the above examples, the whole sentence as a metaphoric frame pattern has been exploited to convey a thought or express a feeling. They are so vivid with an animal image in them that we often find them delightful to the eye and enlightening to our heart. And to top it all, with the consolidation of the mental image the animal idioms evoke in our minds, these animal idioms are always hard to forget, instead, they are entrenched in our cultural and personal memories. 


\section{ANOTHER DISCOVERY: “ANIMAL A COULD BE ANIMAL B" TYPE OF ANIMAL METAPHOR}

During the research process of our present study, we have come to another quite interesting discovery: "ANIMAL A COULD BE ANIMAL B" type of animal metaphor. And we don't feel so strange about this type of employment of animal idioms since in the internet of things, every species of animals is interconnected to each other and there is no "lone wolf" in the world of animal idioms. Let's take a look at the following examples:

Every dog is a lion at home. (One often plays tough in his own home)

A living dog is better than a dead lion. (Better to live than to die)

What's sauce for the goose is sauce for the gander. (What applies to A equally applies to B)

Just as we have mentioned before, this subtype of animal metaphors is a serendipity popped up in our present study. Although this subtype is few and far between in number, they shed light on the important fact that everything is connected in the world, be it animal or human, once it enters the community of living organisms, there is no escaping the fact that they will interact with each other and this interaction process again inevitably finds expression in the corresponding animal idioms.

\section{CONCLUSION}

Language is a crystallization of all the activities, beliefs, values and thinking patterns of human beings. It is also the key to the decoding of cognitive mechanism behind it and the deciphering of culture in which it is embedded. Idioms are the living fossils of a language which afford us a good glimpse of our cognitive operating mechanism. In this paper, we attempt to offer a new interpretation of English animal idioms from conceptual metaphor theory in cognitive linguistics. Language is like a tip of the colossal iceberg called human cognition, and in thinking and categorizing our experiences, a metaphoric concept is usually the underlying code. On the basis of this metaphoric concept systematic cross-domain mappings between two cognitive domains take place and give rise to a host of animal idioms. These animal idioms in turn have enriched our thinking and expressions. Thus we hope that this research attempt can serve as a catalyst for further idiom related studies. Idiom studies can be such meaningful attempts to research language and cognition and to make these attempts deliver more results we need to employ different linguistic theories and perspectives. We do hope that this thesis can turn out to be a worthwhile attempt.
[2] Coulson, S. \& Oakley, T. (2000). Blending basics. Cognitive Linguistics, 11, 175-196.

[3] Coulson, S. \& Oakley, T. (2005). Blending and coded meaning: Literal and figurative meaning in cognitive semantics. Journal of Pragmatics, 37, 1510-1536.

[4] Croft, W. \& Cruse, D. A. (2004). Cognitive linguistics. Cambridge: Cambridge University Press.

[5] Dentith, S. (2000). Parody. London: Routledge

[6] Fauconnier, G. (1985). Mental spaces. Cambridge: MIT Press.

[7] Fauconnier, G. (1994). Mental spaces: Aspects of meaning construction in natural language (pp. 86-100). New York: CUP.

[8] Fauconnier, G. (1997). Mappings in thought and language. New York: Cambridge University Press.

[9] Fauconnier, G. \& Turner, M. (1995). Conceptual integration and formal expression. In M. Johnson (Ed.), Journal of Metaphor and Symbolic Activity, 3, 183-204.

[10] Fauconnier, G. \& Turner, M. (1996). Blending as a central process of grammar. In A. Goldberg (Ed.). Conceptual structure, discourse and language (pp. 113-129). Stanford: Center of the Study of Language and Information (CSLI) Publications.

[11] Fauconnier, G. \& Turner, M. (2002). The way we think: Conceptual blending and the mind's hidden complexities. New York: Basic Books.

[12] Jaszczolt, K. M. (2004). Semantics and pragmatics: Meaning in language and discourse. Beijing: Peking University Press.

[13] Lakoff, G. (1987). Women, fire, and dangerous things: What categories reveal about the mind. Chicago: University of Chicago Press.

[14] Lakoff, G. \& Johnson, M. (1980). Metaphors we live by. Chicago: The University of Chicago Press.

[15] Lakoff, G. \& Johnson, M. (1999). Philosophy in the flesh: The embodied mind and its challenge to western thought. New York: Basic Books.

[16] Langacker, R. W. (1991/2002). Concept, image, and symbol: The cognitive basis of grammar. Berlin: Mounton de Gruyter.

[17] Leech, G. (1983). Principles of pragmatics. London: Longman.

[18] Levinson, S. C. (2001). Pragmatics. Beijing: Foreign Language Teaching and Research Press.

[19] Liu Chunbao. (2012). The English-Chinese Dictionary of Animal Metaphors. Beijing: The Commercial Press.

[20] Mey, J. (2001). Pragmatics: An Introduction. Beijing: Foreign Language Teaching and Research Press.

[21] Sperber, D. \& Wilson, D. (2001). Relevance: Communication and cognition. Beijing: Foreign Language Teaching and Research Press.

[22] Talmy, Leonard. (1985a). Force Dynamics in Language and Thought. In William H. Eilfort, P. Kroeber, and K. Peterson (eds.). Papers from the Parasession on Causatives and Agentivity. Chicago: Chicago Linguistic Society.

[23] Talmy, Leonard. (1985b). Lexicalization Patterns: Semantic Structure in Lexical Forms. In Timothy Shopen(ed.). Language Typology and Syntactic Description, vol. 3. CUP.

[24] Talmy, Leonard. ( 1988). Force Dynamics in Language and Cognition. In Cognitive Science 12.

[25] Ungerer, F. \& Schmid, H. J. (2001). An introduction to cognitive linguistics. Beijing: Foreign Language Teaching and Research Press.

[26] Verschueren, J. (2000). Understanding pragmatics. Beijing: Foreign Language Teaching and Research Press.

\section{REFERENCES}

[1] Coulson, S. (2001). Semantic leaps: Frame shifting and conceptual blending in meaning construction (PP. 1-15). Cambridge: Cambridge University Press. 